\title{
Alendronate sodium hydrate (oral jelly) for the treatment of osteoporosis: review of a novel, easy to swallow formulation
}

This article was published in the following Dove Press journal:

Clinical Interventions in Aging

6 June 2013

Number of times this article has been viewed

\author{
Kazuhiro Imai \\ Department of Life Sciences, \\ Graduate School of Arts and Sciences, \\ The University of Tokyo, Tokyo, Japan
}

Correspondence: Kazuhiro Imai Department of Life Sciences, Graduate School of Arts and Sciences, The University of Tokyo, 3-8-I Komaba, Meguro-ku, Tokyo I53-8902, Japan

$\mathrm{Tel}+8 \mathrm{I} 35454686$ I

Fax +8I 354544317

Email imaik-ort@umin.ac.jp
Abstract: Osteoporosis is a skeletal disorder characterized by loss of bone mass, decreased bone strength, and an increased risk of bone fracture. The disease progresses with age, especially in postmenopausal women. Japan is one of the most rapidly aging societies worldwide. Japanese individuals over 65 years of age constituted $23.0 \%$ of the population in 2010 and $25.1 \%$ to $25.2 \%$ as of 2013. The estimated number of people with osteoporosis in Japan is currently 13 million. Bisphosphonates increase bone mineral density by inhibiting osteoclast-mediated bone resorption, thereby reducing the risk of fractures. Alendronate sodium hydrate (alendronate) is a bisphosphonate that potently inhibits bone resorption and is used to treat osteoporosis. Sufficient water is required to take an alendronate oral tablet; insufficient water could result in digestive system diseases, such as esophageal ulceration. Elderly patients with swallowing difficulty may choke on the tablet. Taking a tablet with oral jelly is a method to prevent digestive system disease and reduce the choking hazard. Once-weekly alendronate oral jelly was approved in 2012 by the Ministry of Health, Labour, and Welfare of Japan as the world's first drug for osteoporosis in a jelly formulation. It consists of a jelly portion and an air portion. The jelly formulation is smoothly discharged by pushing the air portion. Therefore, elderly patients with physical disabilities are able to easily take all of the jelly formulation from the package. In this review, this new formulation of alendronate sodium hydrate (oral jelly) is introduced and discussed in terms of osteoporosis treatment. This new formulation provides an alternative so that patients may select a method of dosing tailored to their preferences. Management of osteoporosis involves assessing fracture risk and preventing fractures. Higher adherence to the treatment of patients with osteoporosis and prevention of osteoporotic fractures are issues to be resolved.

Keywords: air-extruded jelly formulation, alendronate sodium hydrate, bisphosphonate, elderly person, oral jelly, osteoporosis

\section{Introduction}

Osteoporosis is defined as a skeletal disorder characterized by loss of bone mass, decreased bone strength, and increased risk of bone fracture. ${ }^{1}$ The disease progresses with age, especially in postmenopausal women. ${ }^{2}$ Japan is one of the most rapidly aging societies worldwide. According to the National Institute of Population and Social Security Research (Tokyo, Japan), Japanese individuals over 65 years of age constitute $23.0 \%$ of the population in 2010 and $25.1 \%$ to $25.2 \%$ as of 2013 , meaning that more than one in four people in Japan are elderly. According to population-based epidemiologic studies, the estimated number of people with osteoporosis in Japan is 13 million, among which 130,000 suffer from hip fractures every year; 20,000 of these individuals die and 60,000 experience functional decline. The prevalence rate of vertebral fractures in Japan is reportedly comparable with or higher than in Caucasian populations, and is 
approximately $30 \%$ in women in their $70 \mathrm{~s}$ and $40 \%$ in those in their 80 s. $^{3}$ A study of the prevalence of vertebral fractures in Hong Kong, Thailand, Indonesia, and Japan revealed that the prevalence of vertebral fractures in both men and women was highest in Japan for the younger (65-74 years) and older ( $\geq 75$ years) age groups ( $36.6 \%$ and $37.6 \%$ for men, $18.8 \%$ and $28.7 \%$ for women, respectively). ${ }^{4}$

Bisphosphonates are known to increase bone mineral density by inhibiting osteoclast-mediated bone resorption and thereby reduce the risk of fractures. ${ }^{5}$ Several formulations containing bisphosphonates have been applied to the management of osteoporosis. Alendronate sodium hydrate (alendronate) is a bisphosphonate that potently inhibits bone resorption and is used for the treatment of osteoporosis. Alendronate produces a sustained reduction in the levels of biochemical markers of bone remodeling, returning them to the premenopausal range. ${ }^{6,7}$ It also increases bone mineral density ${ }^{6-12}$ and decreases the risk of osteoporotic fracture in postmenopausal women. ${ }^{8-12}$ Long-term intervention studies have shown that continuous alendronate therapy is associated with a sustained therapeutic effect on bone density and remodeling. ${ }^{13,14}$

However, bisphosphonates including alendronate, suppress bone remodeling and thus may prevent the repair of microdamage. Nine patients reportedly developed spontaneous nonspinal fractures after 1 to 8 years of alendronate therapy, and histomorphometric analysis of the bone biopsy samples revealed severe suppression of bone turnover. ${ }^{15}$ In Japan, a patient with insufficiency fractures of the pubis and ilium related to severe suppression of bone turnover after nearly 3 years of alendronate therapy was reported. ${ }^{16}$ Recent papers reported side effects of both atypical femoral fractures and osteonecrosis of the jaw after 7 years of oral alendronate therapy. ${ }^{17}$ Bisphosphonates also have adverse gastrointestinal effects, such as erosions and ulcers in the stomach and small intestine, which are mediated by mitochondrial superoxide production and lipid peroxidation. ${ }^{18}$

Alendronate oral tablets were produced and are used for the treatment of osteoporosis. Water is required with an alendronate oral tablet to help facilitate absorption, and the drug cannot be taken with other foods or drinks. The act of remaining upright for 30 minutes decreases the risk of ulcer formation. Most patients with osteoporosis are elderly. Elderly persons with dysphagia or swallowing difficulty may choke on the tablet. Taking a tablet with oral jelly is a method to prevent digestive system disease and reduce the choking hazard. In this review, this new formulation of alendronate sodium hydrate (oral jelly) is introduced and discussed in the treatment of osteoporosis.

\section{Formulations of oral drugs and packaging containers for elderly patients}

In addition to osteoporosis, many elderly persons suffer from cardiovascular disease, diabetes mellitus, and joint disease. To treat their diseases, they often use multiple oral drugs. There are several formulations of oral drugs (Table 1). Ease of swallowing and handling are preferable for medications, particularly those for elderly patients.

Studies on the construction of new pharmaceutical preparations and new packaging containers that are optimal for administration to elderly people conducted by the Ministry of Health and Welfare of Japan in the 1980s reported that most powder, capsule, tablet, and liquid drug formulations and most packaging containers were suitable for general healthy adults, but not for elderly persons. ${ }^{19}$ Development of new formulations of medicines suitable for elderly individuals with difficulty in swallowing and mastication, dry mouth, and artificial teeth was desired. In 1996, the Ministry of Health and Welfare of Japan reported that jelly, pudding-like, biscuit-like, and wafer-like formulations were preferable for elderly patients. ${ }^{20}$ Biscuit-like and wafer-like formulations were developed as orally disintegrating tablets, which were advanced and popular drug formulations. ${ }^{21}$ The oral jelly formulation was developed as an original formulation in Japan. ${ }^{22}$ Oral jelly formulations have many advantages: ease of swallowing, the ability to take the medication without water, lower risk of accidental ingestion, and optimal masking of drug taste. ${ }^{22}$

In addition to drug formulations, packaging containers optimal for elderly individuals were developed in Japan. There are several types of packaging containers for oral jelly: a single-serving type (Figure 1), a stick type (Figure 2), and an air-extruded type (Table 2). According to a survey among individuals aged 65 and over, the air-extruded type was better than the single-serving type and the stick type. ${ }^{23}$ Elderly persons tend to suffer from a decline in physical performance. It is difficult for the elderly persons to handle the single-serving type when it involved peeling off the container's seal and

Table I Oral drug formulations

\begin{tabular}{lll}
\hline & Advantage & Disadvantage \\
\hline Powder & Rapidly-absorbed & Poor chemical stability \\
Capsule & Drug taste masking & Water is required \\
Tablet & Ease of accurate dosing & Water is required \\
Liquid & Rapidly-absorbed & Poor chemical stability \\
& Ease of swallowing & \\
Jelly & Taken without water & Bulky \\
& Ease of swallowing & \\
\hline
\end{tabular}


taking the jelly formulation with a spoon. For the stick type, it was difficult to take all of the jelly formulation by squeezing the packaging container. An air-extruded jelly formulation was developed as a new formulation comprising the jelly formulation and clean air under increased pressure. ${ }^{22-25}$ The jelly formulation is smoothly discharged by pushing the air portion. Therefore, elderly patients with physical disabilities are able to easily take all of the jelly formulation from the package. The questionnaire survey indicated the applicability of the air-extruded jelly formulation in elderly patients. ${ }^{26}$ A majority of the patients $(63.9 \%, 69$ of 108 subjects) intended to switch their present drug formulation to the airextruded jelly formulation. Especially among subjects who presently took a powder formulation or more than five kinds of medications daily, a high ratio intended to switch to the air-extruded jelly formulation.

\section{Alendronate sodium hydrate (oral jelly)}

Alendronate oral jelly $35 \mathrm{mg}$ (Bonalon ${ }^{\circledR}$ Oral Jelly $35 \mathrm{mg}$; Teijin Pharma Limited, Tokyo, Japan) was approved in 2012 by the Ministry of Health, Labour and Welfare of Japan as the world's first drug for osteoporosis in jelly formulation. Alendronate oral jelly $35 \mathrm{mg}$, administered once a week, was launched in 2012 (Figure 3). Once-weekly alendronate oral jelly comprises a jelly portion and an air portion, which features the air-extruded jelly formulation and makes it easy to take the jelly formulation when pushed by the air. Thus, the active ingredient in the once-weekly alendronate oral tablet $35 \mathrm{mg}$, which has been proven both safe and effective as an osteoporosis treatment, is offered in a jelly formulation.

A dissolution test and bioequivalence study, in accordance with the Japanese Guideline on Bioequivalence Assessment for Development of Additional Formulations and the Japanese Guideline for Bioequivalence Studies of Generic Products, were carried out to evaluate the bioequivalence of alendronate oral jelly $35 \mathrm{mg}$ to the alendronate oral tablet $35 \mathrm{mg} .{ }^{27}$ In the dissolution test, the dissolution profiles of both formulations satisfied the criteria for judgment of similarities

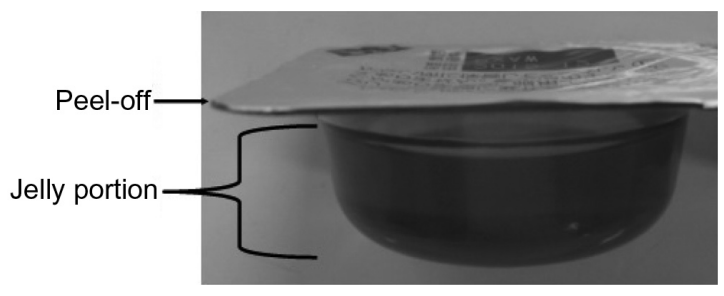

Figure I Oral jelly formulation: single-serving type.

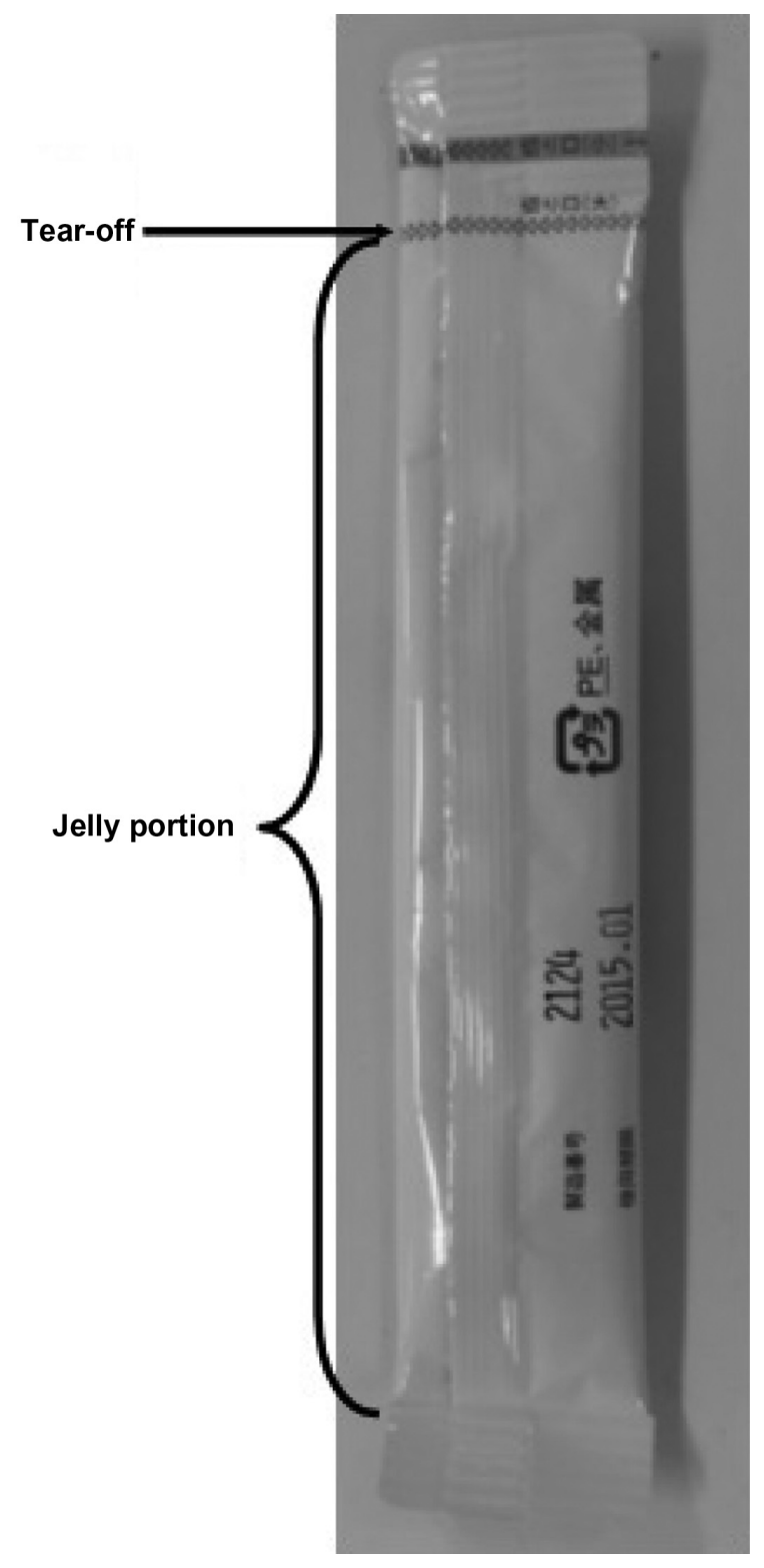

Figure 2 Oral jelly formulation: stick type.

set forth in the Guideline. The bioequivalence study was carried out with an open-label, randomized cross-over (twosequence, two-period) study design and included 32 Japanese healthy adult male volunteers. When the pharmacokinetic parameters of alendronate oral jelly $35 \mathrm{mg}$ and alendronate oral tablet $35 \mathrm{mg}$ were calculated from the serum alendronic acid concentration, the area under the blood concentration time curve (AUC) showed a mean \pm standard deviation of $21.70 \pm 10.20 \mathrm{ng}$ hour $/ \mathrm{mL}$ and $21.33 \pm 13.96 \mathrm{ng}$ hour $/ \mathrm{mL}$, and maximum concentration (Cmax) was $9.60 \pm 4.36 \mathrm{ng} / \mathrm{mL}$ and $9.03 \pm 4.93 \mathrm{ng} / \mathrm{mL}$, respectively (Table 3 ). The serum half-life $\left(t_{1 / 2}\right)$ was $1.54 \pm 0.48$ hours and $1.47 \pm 0.50$ hours, respectively. The mean logarithmic AUC and Cmax were log 
Table 2 Current oral jelly products in Japan

\begin{tabular}{lll}
\hline Active ingredient & Application & $\begin{array}{l}\text { Packaging } \\
\text { container }\end{array}$ \\
\hline $\begin{array}{l}\text { Calcium polystyrene } \\
\text { sulfonate }\end{array}$ & Hyperkalemia & Single-serving \\
lsosorbide & Hydrocephalus & Single-serving \\
Donepezil hydrochloride & Alzheimer's dementia & Single-serving \\
Amlodipine besilate & Hypertension & Stick \\
Lactulose & Hyperammonemia & Stick \\
Aciclovir & Viral infection & Air extruded \\
Cilostazol & Chronic arterial & Air extruded \\
& obstruction & Air extruded \\
\hline
\end{tabular}

(1.049) and $\log (1.050)$, respectively, each within the criteria range, $\log (0.90)$ to $\log (1.11)$, for judgment of bioequivalence with the similarities in dissolution profiles. These results indicate that alendronate oral jelly $35 \mathrm{mg}$ is bioequivalent to alendronate oral tablet $35 \mathrm{mg}$ and suggest no difference in clinical efficacy and safety.

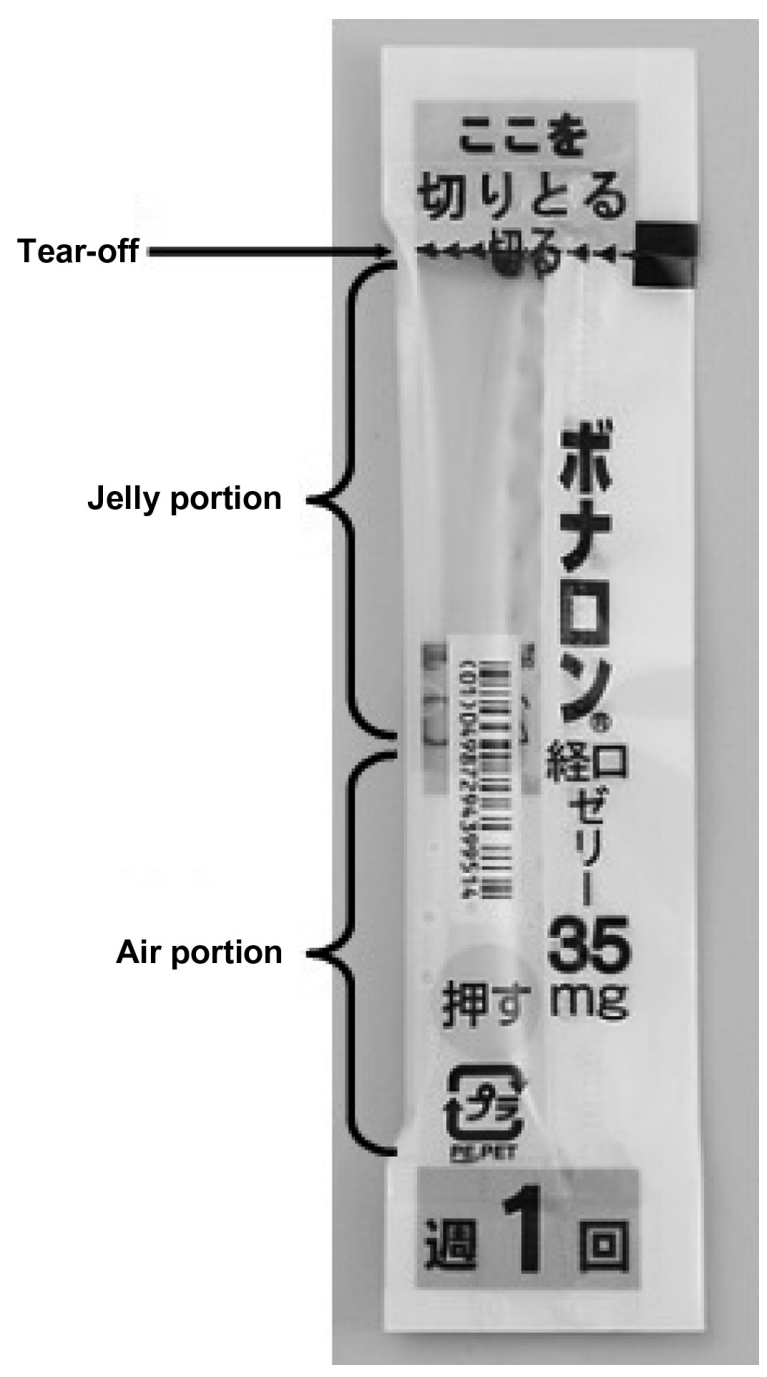

Figure 3 Alendronate oral jelly (Bonalon ${ }^{\circledast}$ Oral Jelly $35 \mathrm{mg}$ ).
Table 3 Serum pharmacokinetic parameters of alendronate

\begin{tabular}{llll}
\hline & $\begin{array}{l}\text { AUC } \\
(\mathbf{n g} \text { hour } / \mathbf{m L})\end{array}$ & $\begin{array}{l}\mathbf{C}_{\max } \\
(\mathbf{n g} / \mathbf{m L})\end{array}$ & $\mathbf{t}_{1 / 2}$ (hour) \\
\hline $\begin{array}{l}\text { Oral jelly } 35 \mathrm{mg} \\
(\mathrm{n}=32)\end{array}$ & $21.70 \pm 10.20$ & $9.60 \pm 4.36$ & $1.54 \pm 0.48$ \\
$\begin{array}{l}\text { Oral tablet } 35 \mathrm{mg} \\
(\mathrm{n}=32)\end{array}$ & $21.33 \pm 13.96$ & $9.03 \pm 4.93$ & $1.47 \pm 0.50$ \\
\hline
\end{tabular}

Note: Values are mean \pm standard deviation.

Abbreviations: AUC, area under the curve; $C_{\max }$, maximum concentration; $t_{1 / 2}$, serum half-life.

\section{Discussion}

In European and American studies, alendronate at a dose of 5 to $20 \mathrm{mg} /$ day has consistently been shown to increase bone mineral density at the spine, hip, and other skeletal sites and to reduce the risk of all types of fractures. ${ }^{6-12,28-32}$ The Fracture Intervention Trial (FIT) comprised two independent but parallel studies with common recruitment conducted at 11 institutions in the United States. The alendronate dosage was $5 \mathrm{mg} /$ day for 2 years, and was then increased to $10 \mathrm{mg} /$ day. ${ }^{8,10}$ In the Phase III study, alendronate dosages ranged from 5 to $20 \mathrm{mg} /$ day. ${ }^{9}$ In The Fosamax international trial (FOSIT) and The Long-Term Care Facilities Study (LTCFS), the alendronate dosage was $10 \mathrm{mg} /$ day.

Compared to Caucasians, Asians have a smaller body size $^{33}$ and a lower dietary intake of calcium. ${ }^{34}$ Because of these racial differences, the recommended drug dose established for Caucasians may not be appropriate for Asians. A small-scale, single-blind study of postmenopausal Japanese women indicated that a dosage of $2.5 \mathrm{mg}$ /day was as effective as a dosage of $10 \mathrm{mg}$ /day in increasing lumbar bone mineral density with 36 weeks of treatment. However, bone turnover markers changed more markedly and rapidly in the $10 \mathrm{mg} /$ day group, and the incidence of adverse effects was higher in the $10 \mathrm{mg} /$ day group. These findings suggest that a $10 \mathrm{mg} /$ day dosage may be an overdosage for Japanese patients. ${ }^{35} \mathrm{~A}$ dose-range finding study in Japan concluded that the optimal daily dose of alendronate is $5 \mathrm{mg}$ in a Japanese population. ${ }^{36}$ The study showed that alendronate at a dosage of $5 \mathrm{mg}$ /day was effective in increasing lumbar bone mineral density, and the incidence of adverse effects was no different compared with the placebo control group after 24 weeks of treatment for Japanese patients with postmenopausal osteoporosis. The study also showed that serum parathyroid hormone and serum 1,25-dihydroxyvitamin D increased only in the $5 \mathrm{mg} /$ day dose group.

Studies to evaluate the effects of alendronate for the treatment of Japanese patients have been carried out. A double-masked multicenter comparative study of Japanese 
patients with osteoporosis indicated that alendronate treatment at a dosage of $5 \mathrm{mg} /$ day for 48 weeks was more efficacious than alfacalcidol for increasing bone mineral density without serious drug-related adverse events. ${ }^{37}$ A 2 year, double-blind comparative study of Japanese patients with osteoporosis indicated that alendronate at a dosage of $5 \mathrm{mg} /$ day significantly lowered the incidence of one or more vertebral fractures to a greater extent than did alfacalcidol after 6 months or more of treatment. ${ }^{38}$ A consecutive 3 year follow-up study of Japanese patients demonstrated that continuous alendronate therapy at $5 \mathrm{mg}$ /day is associated with a sustained therapeutic effect on increasing vertebral bone mineral density and reducing the risk of new vertebral fractures. ${ }^{39}$ A prospective study to assess vertebral strength and mechanical parameters in Japanese women with postmenopausal osteoporosis indicated that vertebral strength significantly increased by $26.9 \%$ from baseline at 12 months of $5 \mathrm{mg} /$ day alendronate, ${ }^{40}$ and by $31.8 \%$ at 18 months, ${ }^{41}$ demonstrating a sustained therapeutic effect.

Once-daily treatment with alendronate has been shown to substantially increase bone mineral density and bone strength and to reduce the incidence of osteoporotic fractures. Dosing convenience is a key element in the effective management of any chronic disease, and is particularly important in the long-term management of osteoporosis. Alendronate must be administered after fasting with water only, at least 30 minutes before the first food of the day, which offers an additional degree of complexity. Thus, it is desirable to reduce the frequency of alendronate dosing without compromising treatment efficacy. Animal data support the rationale that once-weekly dosing with alendronate at $70 \mathrm{mg}$ (seven times the daily oral treatment dose for Caucasians) could provide similar efficacy to that of alendronate at a dosage of $10 \mathrm{mg}$ /day because of its long duration of effect in bone. ${ }^{42-44}$ In addition, animal studies have suggested that the potential for esophageal irritation, observed with daily oral alendronate, might be substantially reduced with once-weekly dosing. ${ }^{45,46}$ A randomized, double-blind, multicenter study to evaluate the efficacy and safety of oral alendronate once- and twice-weekly dosing regimens compared with daily dosing in postmenopausal women with osteoporosis showed that both the once- and twice-weekly dosing regimens fully satisfied the equivalence criteria relative to daily dosing therapy. ${ }^{47,48}$ This study also showed that there were fewer serious upper gastrointestinal adverse experiences and a trend toward a lower incidence of esophageal events in the once-weekly dosing group than in the daily dosing group. The study concluded that once-weekly treatment with alendronate would provide patients with a more convenient, therapeutically equivalent alternative to daily dosing and might enhance compliance and long-term persistence with therapy.

A therapeutic equivalence study of once-weekly and once-daily alendronate was also carried out in Japan. The efficacy and safety of treatment with once-weekly oral alendronate $35 \mathrm{mg}$ were compared with those of once-daily oral alendronate $5 \mathrm{mg}$ in a 52-week, randomized, double-blind, multicenter study of Japanese patients with osteoporosis. ${ }^{49}$ The study concluded that the efficacy and safety of the alendronate $35 \mathrm{mg}$ once-weekly regimen were therapeutically equivalent to those of the alendronate $5 \mathrm{mg}$ once-daily regimen.

For a 12 month period in the United States, a randomized and double-blind study to compare the efficacy and tolerability of once-weekly oral alendronate $70 \mathrm{mg}$ and the oncedaily oral selective estrogen receptor modular raloxifene $60 \mathrm{mg}$ was carried out for the treatment of postmenopausal osteoporosis..$^{50}$ The study concluded that the once-weekly alendronate $70 \mathrm{mg}$ regimen produced significantly greater increases in spine and hip bone mineral density and greater reductions in markers of bone turnover than the once-daily raloxifene $60 \mathrm{mg}$ regimen with similar safety and tolerability profiles. Risedronate is a bisphosphonate that, like alendronate, binds to bone hydroxyapatite and inhibits osteoclastmediated bone resorption. Once-weekly risedronate oral tablets at a dosage of $35 \mathrm{mg} /$ week ( $5 \mathrm{mg}$ /day) have been produced and used to treat osteoporosis.

A study comparing the once-weekly alendronate $70 \mathrm{mg}$ regimen with the once-weekly risedronate $35 \mathrm{mg}$ regimen during 24 months showed that the former yielded significantly greater bone mineral density gains and larger decreases in bone turnover marker levels than the latter, with no difference in gastrointestinal tolerability. ${ }^{51}$

The US Food and Drug Administration approved the once-monthly oral ibandronate sodium tablet as the first once-monthly oral tablet in 2005 . Ibandronate sodium is a bisphosphonate that inhibits bone resorption and is commonly prescribed for the treatment and prevention of postmenopausal osteoporosis. ${ }^{52,53}$ Once-weekly oral bisphosphonates have been associated with higher adherence compared with the once-daily formulations, although overall adherence has remained suboptimal. ${ }^{54-56}$ A study performed to assess whether once-monthly bisphosphonates are associated with improvements in adherence showed no evidence of improved adherence with once-monthly dosing relative to onceweekly dosing, although adherence with either weekly or monthly dosing was significantly better than that with once- 
daily dosing. ${ }^{57}$ These study results suggests that merely reducing the dosing frequency of oral bisphosphonates is not enough to improve adherence.

Alendronate oral jelly, which features the air-extruded jelly formulation, is easy for elderly patients to use and take; most of these patients have physical disabilities and swallowing difficulty. Therefore, this new formulation of osteoporosis treatment may meet individual needs and improve adherence. In addition, alendronate oral jelly with its advantages of ease of swallowing and lower risk of accidental ingestion may reduce the incidence of adverse effects such as esophageal irritation.

Some limitations are apparent regarding alendronate oral jelly. First, there are no published clinical data for its use in the treatment of osteoporosis. An in vivo study to evaluate the use of alendronate sodium gel in the treatment of bone resorptive lesions in periodontitis was carried out. ${ }^{58}$ Osseous defects associated with chronic adult periodontitis were filled with alendronate sodium gel, and flaps were then sutured to obtain primary closures of the interdental papilla in the alendronate gel site. In the control site, the defects were left unfilled. The osseous defect improvement rate in the alendronate gel site after 6 months was $42.85 \%$ and showed significant improvement compared with that of the control site of (7.43\%). In addition, a 6 month, randomized, controlled clinical trial showed that the local delivery of $1 \%$ alendronate gel into periodontal pockets significantly improved bone filling compared with a placebo gel. ${ }^{59}$ Second, alendronate oral jelly is approved and used only in Japan. Clinical data in Japan will lead to approval in other countries. Third, onceweekly dosing of alendronate oral jelly is the only dosing regimen. Other options, such as a once-monthly dosing regimen, will create a variety of osteoporosis treatments to meet individual needs. Intravenous infusion of alendronate for the treatment of osteoporosis is one of these therapeutic options. This preparation may avoid the topical effects of oral alendronate on the gastric mucosa and may provide a useful alternative to oral dosing. A 52-week, multicenter, randomized, double-masked, active-controlled, parallel-group, non-inferiority study of different preparations of alendronate in Japanese patients with osteoporosis, randomly assigned to receive intravenous alendronate $900 \mu \mathrm{g}$ every 4 weeks or oral alendronate $35 \mathrm{mg}$ once weekly was conducted. ${ }^{60}$ The study confirmed that the efficacy and safety of intravenous alendronate $900 \mu \mathrm{g}$ every 4 weeks were similar to those of oral alendronate $35 \mathrm{mg}$ taken once weekly, although the study did not show that intravenous administration might reduce the incidence of gastrointestinal adverse effects. An intravenous infusion of alendronate will provide a new opportunity for effective treatment of patients with osteoporosis who are unable to take oral alendronate or have difficulty complying with the procedures for oral dosing. These new formulations of alendronate oral jelly and intravenous alendronate provide treatment alternatives so that patients may select a method of dosing tailored to their preferences. Management of osteoporosis involves assessing fracture risk and preventing fractures. ${ }^{61}$ Higher adherence of treatment of patients with osteoporosis and prevention of fractures associated with osteoporosis remain issues to be resolved.

\section{Acknowledgments}

The author would like to thank Mr Shozo Komatsu, Mr Nobuaki Miyakawa, and Dr Shigeyuki Ishii for their support.

\section{Disclosure}

The author reports no conflicts of interest in this work.

\section{References}

1. NIH Consensus Development Panel on Osteoporosis Prevention, Diagnosis, and Therapy. Osteoporosis prevention, diagnosis, and therapy. JAMA. 2001;285(69):785-795.

2. Consensus Development Summaries. Estrogen use and postmenopausal women. Sponsored by the National Institute on Aging, assisted by the Office for Medical Applications of Research, NIH. Conn Med. 1980;44(2):85, 87-88.

3. Iki M. Epidemiology of osteoporosis in Japan. Clin Calcium. 2012;22(6); 797-803. Japanese.

4. Kwok AW, Leung JC, Chan AY, et al. Prevalence of vertebral fracture in Asian men and women: comparison between Hong Kong, Thailand, Indonesia and Japan. Public Health. 2012;126(6):523-531.

5. Papapoulos SE. The role of bisphosphonates in the prevention and treatment of osteoporosis. Am J Med. 1993;95(5A):48S-52S.

6. Tucci JR, Tonino RP, Emkey RD, Peverly CA, Kher U, Santora AC 2nd. Effect of three years of oral alendronate treatment in postmenopausal women with osteoporosis. Am J Med. 1996;101(5):488-501.

7. Devogelaer JP, Broll H, Correa-Rotter R, et al. Oral alendronate induces progressive increases in bone mass of the spine, hip, and total body over 3 years in postmenopausal women with osteoporosis. Bone. 1996;18(2): $141-150$.

8. Black DM, Cummings SR, Karpf DB, et al. Randomised trial of effect of alendronate on risk of fracture in women with existing vertebral fractures. Fracture Intervention Trial Research Group. Lancet. 1996;348(9041): 1535-1541.

9. Liberman UA, Weiss SR, Broll J, et al. Effect of oral alendronate on bone mineral density and the incidence of fractures in postmenopausal osteoporosis. The Alendronate Phase III Osteoporosis Treatment Study Group. N Engl J Med. 1995;333(22):1437-1443.

10. Cummings SR, Black DM, Thompson DE, Applegate WB, Barrett-Connor E, Musliner TA, Palermo L, Prineas R, Rubin SM, Scott JC, Vogt T, Wallace R, Yates AJ, LaCroix AZ. Effect of alendronate on risk of fracture in women with low bone density but without vertebral fractures: results from the Fracture Intervention Trial. JAMA. 1998;280(24):2077-2082. 
11. Pols HA, Felsenberg D, Hanley DA, et al. Multinational, placebocontrolled, randomized trial of the effects of alendronate on bone density and fracture risk in postmenopausal women with low bone mass: results of the FOSIT study. Fosamax International Trial Study Group. Osteoporos Int. 1999;9(5):461-468.

12. Ensrud KE, Black DM, Palermo L, et al. Treatment with alendronate prevents fractures in women at highest risk: results from the Fracture Intervention Trial. Arch Intern Med. 1997;157(22):2617-2624.

13. Bone HG, Hosking D, Devogelaer JP, et al; Alendronate Phase III Osteoporosis Treatment Study Group. Ten years' experience with alendronate for osteoporosis in postmenopausal women. $N \mathrm{Engl} \mathrm{J} \mathrm{Med}$. 2004;350(12):1189-1199.

14. Ensrud KE, Barrett-Connor EL, Schwartz A, et al; Fracture Intervention Trial long-Term Extension Research Group. Randomized trial of effect of alendronate continuation versus discontinuation in women with low BMD: results from the Fracture Intervention Trial long-term extension. J Bone Miner Res. 2004;19(8):1259-1269.

15. Odvina CV, Zerwekh JE, Rao DS, Maalouf N, Gottschalk FA, Pak CY. Severely suppressed bone turnover: a potential complication of alendronate therapy. J Clin Endocrinol Metab. 2005;90(3):1294-1301.

16. Imai K, Yamamoto S, Anamizu Y, Horiuchi T. Pelvic insufficiency fracture associated with severe suppression of bone turnover by alendronate therapy. J Bone Miner Metab. 2007;25(5):333-336.

17. Chiu WY, Lee JJ, Tsai KS. Atypical femoral fractures shortly after osteonecrosis of the jaw in a postmenopausal woman taking alendronate for osteoporosis. J Clin Endocrinol Metab. 2013;98(4):E723-E726.

18. Nagano Y, Matsui H, Shimokawa O, et al. Bisphosphonate-induced gastrointestinal mucosal injury is mediated by mitochondrial superoxide production and lipid peroxidation. J Clin Biochem Nutr. 2012;51(3): 196-203.

19. Sugihara M, Awazu S, Ueda K, Takeda Y, Fukumuro K. [Studies for the construction of new pharmaceutical preparations and new packaging containers optimal for administration to elderly subjects]. 1988. Japanese.

20. Sugihara M. The Pharmaceuticals Monthly. 1996;38:1703-1706. Japanese.

21. Mostafa HF, Ibrahim MA, Sakr A. Development and optimization of dextromethorphan hydrobromide oral disintegrating tablets: effect of formulation and process variables. Pharm Dev Technol. 2013;18(2): 454-463.

22. Dairaku M, Togashi M. Development of Air Push Jelly Formulation and Packaging Design. Hosogijutsu Zasshi (Japan Packaging Institute). 2003;41(10):836-841. Japanese.

23. Sakashita Y, Sakurai S, Yakou S, Ishizuka H, Yanagawa C. Clinical usefulness of jelly preparation, new formulation for medical drug. Pharm Tech Japan. 2003;19(13):2367-2377. Japanese.

24. Dairaku M, Togashi M. Development of Air Push Jelly Formulation. Yakuzaigaku (J pharm sci technol Japan). 2005;65(4):209-214. Japanese.

25. Hanawa T. Development of the new oral dosage forms for elderly patients. Nippon Ronen Igakkai Zasshi. 2008;45(5):485-488. Japanese.

26. Hanawa T, Tokutake N, Oguchi T. Questionnaire survey of air extruded jelly dosage form (I) - oral condition of elder patients and applicability of air extruded jelly formulation - . Yakugaku Zasshi. 2012;132(12): 1461-1466. Japanese.

27. Fukase H, Miyagi F, Saito K, Ito N. Bioequivalence of Bonalon ${ }^{\circledR}$ Oral Jelly $35 \mathrm{mg}$ versus Bonalon ${ }^{\circledR}$ Tablet $35 \mathrm{mg}$. Shinyaku and Rinsho (Journal of New Remedies and Clinics). 2012;61(9): 1833-1847. Japanese.

28. Karpf DB, Shapiro DR, Seeman E, et al. Prevention of nonvertebral fractures by alendronate. A meta-analysis. Alendronate Osteoporosis Treatment Study Groups. JAMA. 1997;277(14):1159-1164.

29. Sharpe M, Noble S, Spencer CM. Alendronate: an update of its use in osteoporosis. Drugs. 2001;61(7):999-1039.

30. Cranney A, Wells G, Willan A, et al; Osteoporosis Methodology Group and The Osteoporosis Research Advisory Group. Meta-analyses of therapies for postmenopausal osteoporosis. II. Meta-analysis of alendronate for the treatment of postmenopausal women. Endocr Rev. 2002;23(4):508-516.
31. Greenspan SL, Schneider DL, McClung MR, et al. Alendronate improves bone mineral density in elderly women with osteoporosis residing in long-term care facilities. A randomized, double-blind, placebo-controlled trial. Ann Intern Med. 2002;136(10):742-746.

32. Papapoulos SE, Quandt SA, Liberman UA, Hochberg MC, Thompson DE. Meta-analysis of the efficacy of alendronate for the prevention of hip fractures in postmenopausal women. Osteoporos Int. 2005;16(5):468-474.

33. Davis JW, Novotny R, Ross PD, Wasnich RD. The peak bone mass of Hawaiian, Filipino, Japanese, and white women living in Hawaii. Calcif Tissue Int. 1994;55(4):249-252.

34. Nordin BE. International patterns of osteoporosis. Clin Orthop Relates Res. 1966;45:17-30.

35. Shiraki M, Kushida K, Fukunaga M, et al. A placebo-controlled, single-blind study to determine the appropriate alendronate dosage in postmenopausal Japanese patients with osteoporosis. The Alendronate Research Group. Endocr J. 1998;45(2):191-201.

36. Nakamura T, Kushida K, Shiraki M, et al. Dose-range finding study of alendronate in the treatment of the patients with involutional osteoporosis and postmenopausal women. JNew Remedies Clin. 1997;35:3-17. Japanese.

37. Shiraki M, Kushida K, Fukunaga M, et al. A double-masked multicenter comparative study between alendronate and alfacalcidol in Japanese patients with osteoporosis. The Alendronate Phase III Osteoporosis Treatment Research Group. Osteoporos Int. 1999;10(3):183-192.

38. Kushida K, Shiraki M, Nakamura T, et al. The efficacy of alendronate in reducing the risk for vertebral fracture in Japanese patients with osteoporosis: a randomized, double-blind, active-controlled, doubledummy trial. Curr Ther Res Clin Exp. 2002;63:606-620.

39. Kushida K, Shiraki M, Nakamura T, et al. Alendronate reduced vertebral fracture risk in postmenopausal Japanese women with osteoporosis: a 3-year follow-up study. J Bone Miner Metab. 2004;22(5):462-468.

40. Imai K, Ohnishi I, Matsumoto T, Yamamoto S, Nakamura K. Assessment of vertebral fracture risk and therapeutic effects of alendronate in postmenopausal women using a quantitative computed tomography-based nonlinear finite element method. Osteoporosis Int. 2009;20(5):801-810.

41. Imai K. Vertebral fracture risk and alendronate effects on osteoporosis assessed by a computed tomography-based nonlinear finite element method. J Bone Miner Metab. 2011;29(6):645-651.

42. Seedor JG, Quartuccio HA, Thompson DD. The bisphosphonate alendronate (MK-217) inhibits bone loss due to ovariectomy in rats. J Bone Miner Res. 1991;6(4):339-346.

43. Balena R, Toolan BC, Shea M, et al. The effects of 2-year treatment with the aminobisphosphonate alendronate on bone metabolism, bone histomorphometry, and bone strength in ovariectomized nonhuman primates. J Clin Invest. 1993;92(6):2577-2586.

44. Porras AG, Holland SD, Gertz BJ. Pharmacokinetics of alendronate. Clin Pharmacokinet. 1999;36(5):315-328.

45. Peter CP, Handt LK, Smith SM. Esophageal irritation due to alendronate sodium tablets: possible mechanisms. Dig Dis Sci. 1998;43(9): 1998-2002.

46. Bone HG, Adami S, Rizzoli R, et al. Weekly administration of alendronate: rationale and plan for clinical assessment. Clin Ther. 2000;22(1):15-28.

47. Schnitzer T, Bone HG, Crepaldi G, et al. Therapeutic equivalence of alendronate $70 \mathrm{mg}$ once-weekly and alendronate $10 \mathrm{mg}$ daily in the treatment of osteoporosis. Alendronate Once-Weekly Study Group. Aging. 2000;12(1):1-12.

48. Rizzoli R, Greenspan SL, Bone G 3rd, et al; Alendronate Once-Weekly Study Group. Two-year results of once-weekly administration of alendronate $70 \mathrm{mg}$ for the treatment of postmenopausal osteoporosis. J Bone Miner Res. 2002;17(11):1988-1996.

49. Uchida S, Taniguchi T, Shimizu T, et al. Therapeutic effects of alendronate $35 \mathrm{mg}$ once weekly and $5 \mathrm{mg}$ once daily in Japanese patients with osteoporosis: a double-blind, randomized study. J Bone Miner Metab. 2005;23(5):382-388.

50. Luckey M, Kagan R, Greenspan S, et al. Once-weekly alendronate $70 \mathrm{mg}$ and raloxifene $60 \mathrm{mg}$ daily in the treatment of postmenopausal osteoporosis. Menopause. 2004;11(4):405-415. 
51. Reid DM, Hosking D, Kendler D, et al. A comparison of the effect of alendronate and risedronate on bone mineral density in postmenopausal women with osteoporosis: 24-month results from FACTS-International. Int J Clin Pract. 2008;62(4):575-584.

52. Chesnut III CH, Skag A, Christiansen C, et al; Oral Ibandronate Osteoporosis Vertebral Fracture Trial in North America and Europe (BONE). Effects of oral ibandronate administered daily or intermittently on fracture risk in postmenopausal osteoporosis. J Bone Miner Res. 2004;19(8):1241-1249.

53. Delmas PD, Recker RR, Chesnut CH III, et al. Daily and intermittent oral ibandronate normalize bone turnover and provide significant reduction in vertebral fracture risk: results from the BONE study. Osteoporos Int. 2004;15(10):792-798.

54. Recker RR, Gallagher R, MacCosbe PE. Effect of dosing frequency on bisphosphonate medication adherence in a large longitudinal cohort of women. Mayo Clin Proc. 2005;80(7):856-861.

55. Cramer JA, Amonkar MM, Hebborn A, Altman R. Compliance and persistence with bisphosphonate dosing regimens among women with postmenopausal osteoporosis. Curr Med Res Opin. 2005;21(9): 1453-1460.

56. Cramer JA, Silverman S. Persistence with bisphosphonate treatment for osteoporosis: finding the root of the problem. Am J Med. 2006; 119(4 Suppl 1):S12-S17.
57. Briesacher BA, Andrade SE, Harrold LR, Fouayzi H, Yood RA. Adoption of once-monthly oral bisphosphonates and the impact on adherence. Am J Med. 2010;123(3):275-280.

58. Reddy GT, Kumar TM, Veena. Formulation and evaluation of Alendronate Sodium gel for the treatment of bone resorptive lesions in Periodontitis. Drug Deliv. 2005;12(4):217-222.

59. Sharma A, Pradeep AR. Clinical efficacy of $1 \%$ alendronate gel as a local drug delivery system in the treatment of chronic periodontitis: a randomized, controlled clinical trial. J Periodontol. 2012;83(1):11-18.

60. Shiraki M, Nakamura T, Fukunaga M, Sone T, Usami A, Inoue T. A multicenter randomized double-masked comparative study of different preparations of alendronate in osteoporosis - monthly (four weeks) intravenous versus once weekly oral administrations. Curr Med Res Opin. 2012;28(8):1357-1367.

61. Imai K. Management of osteoporosis: assessment of fracture risk and therapeutic effects on osteoporosis. In: Pena AR, Perez VO, editors. Osteoporosis: Risk Factors, Symptoms and Management. New York: Nova Science; 2012:67-91.
Clinical Interventions in Aging

\section{Publish your work in this journal}

Clinical Interventions in Aging is an international, peer-reviewed journal focusing on evidence-based reports on the value or lack thereof of treatments intended to prevent or delay the onset of maladaptive correlates of aging in human beings. This journal is indexed on PubMed Central, MedLine, the American Chemical Society's 'Chemical Abstracts

\section{Dovepress}

Service' (CAS), Scopus and the Elsevier Bibliographic databases. The manuscript management system is completely online and includes a very quick and fair peer-review system, which is all easy to use. Visit http://www.dovepress.com/testimonials.php to read real quotes from published authors. 